\title{
BIOMETALS 2008 (Santiago de Compostela)
}

\author{
Manuel L. Lemos
}

Published online: 7 January 2009

(C) Springer Science+Business Media, LLC. 2008

This BioMetals issue contains some selected presentations of the invited speakers given at the 6th International BioMetals Symposium (BioMetals 2008), which was held in Santiago de Compostela (Spain) from 14th to 18th July 2008 (Fig. 1). The Symposium was really a great success with almost 200 participants from more than 20 countries who enjoyed the science but also the nice weather, the food and the social events. The scientific program included several sessions dedicated to siderophores and iron transport, metal transport, metals and disease, toxic metals, heme transport, metal-protein interactions and metals and gene regulation. The articles in this collection represent the talks given in the different sessions and I think they show the enormous advance in our knowledge about the role of metals in biological systems, and also open a great number of new questions, demonstrating the vitality of the Biometals field.

Continuing with an initiative started in the 5th International Biometals Symposium celebrated in Oregon (USA) in 2006, and hosted by Prof. Jorge H. Crosa, we bestowed the Igor Stojiljkovic Memorial Awards. The Lecturer Award was given to Prof. James Camakaris (Fig. 2), from the University of

M. L. Lemos $(\bowtie)$

Microbiology and Parasitology, Institute of Aquaculture, Campus Sur s/n, Santiago de Compostela, University of Santiago de Compostela, 15782 La Coruña, Spain

e-mail: manuel.lemos@usc.es
Melbourne (Australia), for his outstanding contributions to the biometals field. He gave the closing lecture of the meeting and his talk is also summarized in an article in this special issue. The postdoctoral award was given to Dr. Anna Zawadzka from the group of Prof. Kenneth Raymond at the University of California at Berkeley (USA). Ms. Doreen Koch, from the group of Prof. Dietrich Nies at the MartinLuther University (Germany), was awarded with the graduate student award. I am deeply indebted to Prof. Jorge H. Crosa (Oregon Health \& Science University, USA) for getting the funds for these awards from the Emory University Memorial fund. Also, for the first time in this meeting series, Springer-the publisher of this journal-funded a prize for the best poster presented at the meeting. The awardee was Mr. James Butcher from the Alan Stintzi laboratory in the University of Ottawa (Canada). I hope these awards can be continued and even increased on the next Biometals symposia since they will encourage the participation and stimulate the preparation of good posters and presentations, especially by young scientists. The selection Committee for these awards were the members of the International Committee plus some others chairs of sessions. All Committee members highlighted the impressive scientific level of posters and oral presentations that made it really difficult to select a winner for each category.

I hope that reading the chapters will bring those of you who attended the meeting back to joyful days in Spain. 


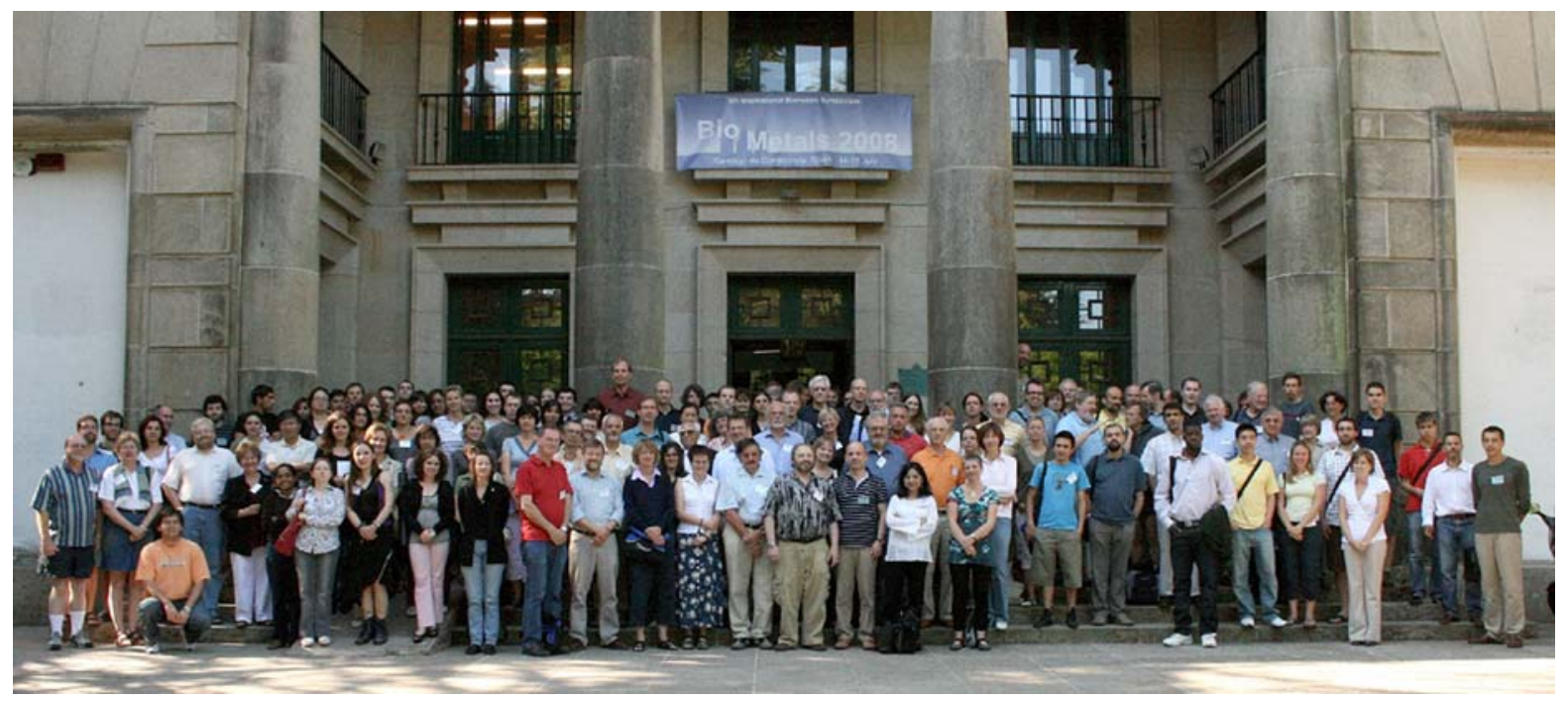

Fig. 1 Group photo of the 6th International Biometals Symposium

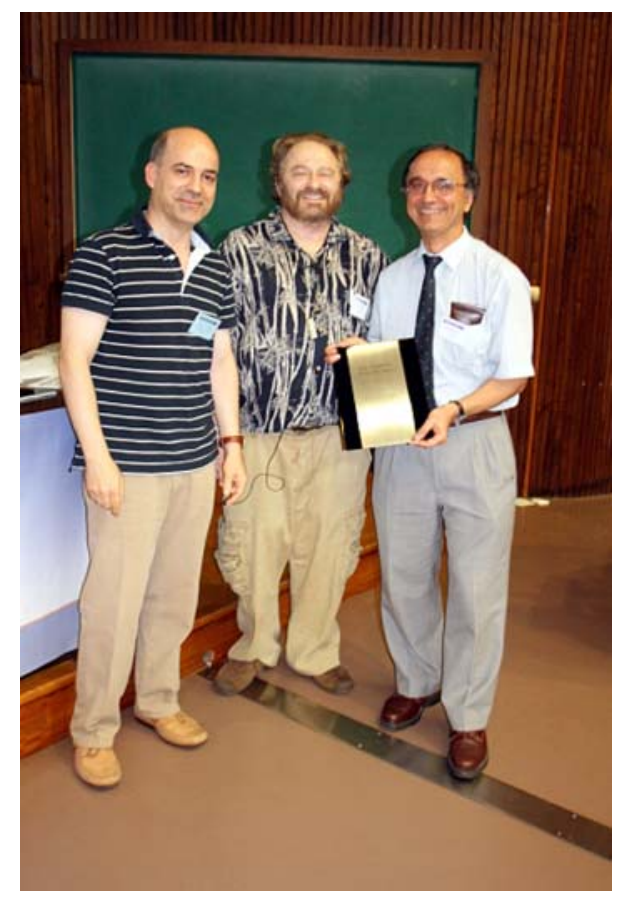

The 7th International Biometals Symposium will be held in Tucson, Arizona (USA) in 2010, hosted by Dr. Christopher Rensing from the University of Arizona. I wish the organizers good luck and a great success in the meeting organization and I hope that all attendees at Santiago de Compostela can meet again in the sunny and beautiful Arizona.

Acknowledgments I am grateful for the kind support of Prof. Guenther Winkelmann, Editor-in-Chief of BioMetals, and the Springer editorial staff for making this publication possible.

Fig. 2 Igor Stojiljkovic Memorial Lecturer Award presented to Prof. Jim Camakaris by Jorge Crosa and Manuel Lemos 